\title{
Malignant Sarcomatous Transformation of Benign Giant Cell Tumor of Bone after Treatment with Denosumab Therapy: A Literature Review of Reported Cases
}

Sadiq I. Alaqaili ${ }^{1}$, Abbas M. Abduljabbar ${ }^{2}$, Ali J. Altaho ${ }^{3}$, Abdulrahman A. Khan ${ }^{1}$, Jawaher A. Alherabi ${ }^{4}$

1. Miscellaneous, Alfaisal University, Riyadh, SAU 2. Emergency Medicine, Dammam University, Qatif, SAU 3. Neurology, King Faisal University, Alahsa, SAU 4. Orthopaedics, Alfaisal University, Riyadh, SAU

Corresponding author: Sadiq I. Alaqaili, salaqaili@alfaisal.edu

\begin{abstract}
Giant cell tumor of bone (GCTB) is a biologically benign and locally aggressive tumor that most often affects the epiphyseal and metaphyseal sites of long bones in the young adult population. Overexpression of receptor activator of nuclear factor kappa B ligand (RANKL) by cancerous mesenchymal stromal cells stimulates a signal transduction cascade that recruits and activates multinucleated osteoclast-like giant cells, resulting in pathologic bone resorption. Denosumab, an RANKL inhibitor that blocks the RANKLmediated osteoclast activation, has been recently approved by the United States Food and Drug Administration (FDA) for the treatment of aggressive GCTB. Although uncommon, several studies reported drug-related malignant morphological transformation of benign GCTB following treatment with denosumab therapy. The aim of the article was to review the clinicopathological characteristics of all the reported cases of malignant sarcomatous transformation of GCTB after treatment with denosumab therapy in patients without any history of prior exposure to radiotherapy.
\end{abstract}

Categories: General Surgery, Oncology, Orthopedics

Keywords: giant cell tumor of bone, malignant, sarcoma, transformation, denosumab, receptor activator of nuclear factor kappa b

\section{Introduction And Background}

Giant cell tumor of bone (GCTB) is a benign osteolytic neoplasm that primarily involves the epiphyseal and metaphyseal regions of long bones [1]. Although biologically benign, GCTB is characterized by local aggressiveness and destructive invasion into the neighboring soft tissues [2]. Around $80 \%$ to $85 \%$ of GCTB patients present to clinics with primary locally advanced neoplasms that are not amenable to surgical management [3].

Received 12/20/2018

Review began 12/22/2018 Review ended 12/26/2018 Published 12/28/2018

๑) Copyright 2018 Alaqaili et al. This is an open access article distributed under the terms of the Creative Commons Attribution License CC-BY 3.0., which permits unrestricted use, distribution, and reproduction in any medium, provided the original author and source are credited.
The optimal management of GCTB continues to be controversial [4]. Nonetheless, surgery is the preferred standard of care as it offers curative treatment whenever technically feasible [3]. Surgical treatment choices comprise intralesional curettage and en bloc resection [3]. Surgery is generally associated with variable degrees of functional morbidity. Moreover, the rates of local recurrence are highly dependent on the type of surgery and tumor characteristics (for example, tumor site and size) [5].

From a histological point of view, GCTB has a distinctive bi-phenotypic cell pathology. GCTB comprises osteoclast-like multinucleated giant cells that express receptor activator of nuclear factor kappa B (RANK) and neoplastic mesenchymal stromal cells that express RANK ligand (RANKL). In patients with GCTB, the RANK-RANKL interaction mediates the differentiation and activation of osteoclasts and thus results in the osteolytic phenotype of bone destruction $[3,6-8]$.

Denosumab is a fully humanized monoclonal antibody that targets RANKL. Thus, denosumab inhibits the RANK-RANKL interaction and prevents bone destruction [9]. In mid-2013, denosumab was green-lighted by the United States Food and Drug Administration (FDA) for the treatment of adults and skeletally mature adolescents with GCTB that is inoperable, or initial surgery is expected to yield considerable morbidity [3,910].

Several studies including clinical trials [3,10-12], case series [13-20] and case reports [21-24] have shown beneficial advantages of the utility of preoperative denosumab in the management of GCTB. Such beneficial advantages included delayed tumor progression, tumor downstaging, reduced surgical morbidity, facilitation of salvageable surgery and achievement of pre-defined therapeutic

clinical/radiological/histological responses. Moreover, little is known about the local recurrence rate of GCTB following preoperative denosumab and successive intralesional curettage [20]. 
Prior exposure to radiation therapy has been proposed as a predisposing factor for the development of malignant transformation of GCTB [3]. Although extremely uncommon, true spontaneous malignant transformation of GCTB without prior exposure to radiation therapy has been reported in the literature [2528]. Moreover, in patients without prior exposure to radiation therapy, several studies documented cases of malignant sarcomatous transformation of GCTB during or after denosumab therapy [29]. This has led to raising an alarming concern about a possible causal relationship between the malignant sarcomatous transformation of GCTB and denosumab therapy. However, to the best of knowledge, no article has previously summarized all the related reported cases. Therefore, the aim of this article was to provide a retrospective and narrative review of all the cases of malignant sarcomatous transformation of GCTB during or after denosumab therapy in patients without prior exposure to radiation therapy.

\section{Review}

PubMed ${ }^{\circledR}$ database was searched until 15th December 2018 using the following keywords: "giant cell tumor of bone", "denosumab", and "malignant transformation". Only English-published literature was included. Further references from published articles were also manually screened for potential additional studies. The study inclusion criteria included patients who were (i) initially diagnosed with benign GCTB, (ii) received denosumab therapy, (iii) developed malignant sarcomatous transformation during or post-therapy, and (iv) did not have any history of previous exposure to radiation therapy. For each reported case of sarcomatous transformation of GCTB during or after denosumab therapy, the following details were reported (whenever available): authors, year of publication, patient age, patient gender, tumor site, sarcoma histology, pulmonary metastases, causal relationship with denosumab therapy, time of sarcomatous transformation from the time of denosumab therapy, and duration of denosumab therapy.

In 2010, Thomas et al. [3] reported two patients who developed a sarcomatous transformation of GCTB. The first patient developed a high-grade sarcoma in the upper extremity during preoperative denosumab therapy. The second patient developed a metastatic malignant GCTB to the lung that was diagnosed eight months after cessation of denosumab therapy. The duration of denosumab therapy ranged from three to seven months. The authors stated that none of these two cases of sarcomatous transformation of GCTB were related to denosumab therapy.

In 2013, Chawla and colleagues [10] reported two patients who developed sarcomatous transformation of GCTB during preoperative denosumab therapy. In the first patient, the sarcoma was assumed to be present at the time of initial clinical presentation and probably was missed during the initial core biopsy sampling. In the second patient, the sarcoma was assumed to be a true malignant transformation of benign GCTB.

In 2015, Rutkowski and associates [11] reported two patients who developed sarcomatous transformation of GCTB in the pelvis and sacrum during preoperative denosumab therapy. The duration of preoperative denosumab therapy was roughly nine months. However, the authors indicated that none of these two cases of sarcomatous transformation of GCTB were related to denosumab therapy. Moreover, the authors pinpointed that a diagnosis of primary malignant GCTB might have been missed by sampling error at the time of initial core biopsy.

In 2015, Aponte-Tinao and partners [30] reported a 19-year-old female who developed a high-grade pleomorphic sarcoma in the proximal tibia while receiving preoperative denosumab therapy. The malignant sarcomatous transformation of GCTB originated from a recurrent benign GCTB lesion in the same initial site of the proximal tibia. The duration of preoperative denosumab therapy was 13 months. The sarcomatous transformation of GCTB was diagnosed at 13 months of denosumab therapy when a suspicious mass was clinically palpated in the popliteal fossa. The authors related the malignant sarcomatous transformation of GCTB to denosumab therapy.

In 2015, Broehm and friends [31] reported two patients who developed a sarcomatous transformation of GCTB. The first patient was a 59-year-old male with a 12 -year history of GCTB and multiple recurrences. The patient developed a high-grade spindle cell osteosarcoma in the initial site (ischium) while receiving preoperative denosumab therapy. The duration of preoperative denosumab therapy was 30 months. The sarcomatous transformation of GCTB was diagnosed at 30 months of denosumab therapy. Metastatic nodules in the lungs were also detected on computed tomography scan. The second patient was a 56 -yearold male with a seven-year history of GCTB. The patient developed a high-grade spindle cell osteosarcoma in the initial site (distal femur) while receiving preoperative denosumab therapy. The duration of preoperative denosumab therapy was six months. The authors related the malignant sarcomatous transformation of GCTB to denosumab therapy.

In 2016, Park and peers [32] reported a 30-year-old male patient who developed malignant transformation of GCTB after 20 months of denosumab therapy. The patient developed high-grade sarcoma at the site of initial lesion (pelvis) as well as pulmonary metastases. The authors related the malignant sarcomatous transformation of GCTB to denosumab therapy.

In 2017, Tsukamoto and co-workers [33] reported one patient who developed sarcomatous transformation of 
GCTB after treatment with preoperative denosumab. The patient was a 29-year-old woman who underwent intralesional curettage of a GCTB in the left ischium. Approximately ten years after the initial surgery, the patient developed a recurrence of GCTB in the same original site. The patient received preoperative denosumab therapy for six months. At six months, a computed tomography scan showed a rapidly growing lesion in the left ischium. A histopathological examination of the incisional biopsy was consistent with high-grade osteosarcoma. The patient progressed clinically and developed pulmonary metastases and eventually died. The authors related the malignant sarcomatous transformation of GCTB to denosumab therapy.

Table 1 shows a summary of the published studies on malignant sarcomatous transformation of benign GCTB following treatment with denosumab therapy. To the best of knowledge, 11 related cases have been reported so far in the English literature. In five cases, the authors declined a causal relationship between the malignant sarcomatous transformation of GCTB and denosumab therapy. In six cases, the authors related the malignant sarcomatous transformation of GCTB to denosumab therapy. High-grade osteosarcoma was the most common tumor histology. All cases of malignant sarcomatous transformation of GCTB occurred in the initial site of the tumor, and four patients developed malignant pulmonary metastases. The duration of denosumab therapy ranged from six to 30 months.

\begin{tabular}{|c|c|c|c|c|c|c|c|c|c|c|}
\hline Ref & Authors & Year & $\begin{array}{l}\text { Patient } \\
\text { (n) }\end{array}$ & Sex & $\begin{array}{l}\text { Age } \\
\text { (years) }\end{array}$ & $\begin{array}{l}\text { Tumor } \\
\text { location }\end{array}$ & Tumor histology & $\begin{array}{l}\text { Pulmonary } \\
\text { metastases }\end{array}$ & $\begin{array}{l}\text { Causal relationship } \\
\text { with denosumab } \\
\text { therapy }\end{array}$ & $\begin{array}{l}\text { Duration of } \\
\text { denosumab } \\
\text { therapy }\end{array}$ \\
\hline \multirow[t]{2}{*}{ [3] } & \multirow{2}{*}{$\begin{array}{l}\text { Thomas et } \\
\text { al. }\end{array}$} & \multirow[t]{2}{*}{2010} & 1 & NM & NM & $\begin{array}{l}\text { Upper } \\
\text { extremity }\end{array}$ & $\begin{array}{l}\text { High-grade } \\
\text { sarcoma }\end{array}$ & $N R$ & No & 3-7 months \\
\hline & & & 1 & NM & NM & NM & Malignant GCTB & Yes & No & 3-7 months \\
\hline \multirow{2}{*}{ [10] } & \multirow{2}{*}{$\begin{array}{l}\text { Chawla et } \\
\text { al. }\end{array}$} & \multirow{2}{*}{2013} & 1 & NM & NM & NM & NM & NM & No & NM \\
\hline & & & 1 & NM & NM & NM & NM & NM & Yes & NM \\
\hline \multirow{2}{*}{ [11] } & \multirow{2}{*}{$\begin{array}{l}\text { Rutkowski } \\
\text { et al. }\end{array}$} & \multirow{2}{*}{2015} & 1 & NM & NM & Pelvis & NM & NM & No & 9.2 months \\
\hline & & & 1 & NM & NM & Sacrum & NM & NM & No & 9.2 months \\
\hline [30] & $\begin{array}{l}\text { Aponte- } \\
\text { Tinao et al. }\end{array}$ & 2015 & 1 & Female & 19 & $\begin{array}{l}\text { Proximal } \\
\text { tibia }\end{array}$ & $\begin{array}{l}\text { High-grade } \\
\text { pleomorphic } \\
\text { sarcoma }\end{array}$ & NM & Yes & 13 months \\
\hline \multirow{2}{*}{ [31] } & \multirow{2}{*}{$\begin{array}{l}\text { Broehm et } \\
\text { al. }\end{array}$} & \multirow{2}{*}{20} & 1 & Male & 59 & Ischium & $\begin{array}{l}\text { High-grade spindle } \\
\text { cell osteosarcoma }\end{array}$ & Yes & Yes & 30 months \\
\hline & & & 1 & Male & 56 & $\begin{array}{l}\text { Distal } \\
\text { femur }\end{array}$ & $\begin{array}{l}\text { High-grade spindle } \\
\text { cell osteosarcoma }\end{array}$ & NM & Yes & 6 months \\
\hline [32] & Park et al. & 2016 & 1 & Male & 30 & Pelvis & $\begin{array}{l}\text { High-grade } \\
\text { sarcoma }\end{array}$ & Yes & Yes & 20 months \\
\hline [33] & $\begin{array}{l}\text { Tsukamoto } \\
\text { et al. }\end{array}$ & 2017 & 1 & Female & 29 & Ischium & $\begin{array}{l}\text { High-grade } \\
\text { osteosarcoma }\end{array}$ & Yes & Yes & 6 months \\
\hline
\end{tabular}

TABLE 1: Summary of all published studies about malignant sarcomatous transformation of giant cell tumor of bone during and after denosumab therapy

GCTB: giant cell tumor of bone; NM: not mentioned; Ref: reference

The exact mechanism by which the sarcomatous transformation of GCTB occurs during or after denosumab therapy is poorly defined [33]. However, from a molecular point of view, three potential hypotheses are proposed. First, RANKL expression contributes substantial roles in B- and T-cell differentiation as well as dendritic cell survival [34-36]. Thus, the inhibition of RANKL expression by denosumab therapy is expected to lead to immunosuppression and subsequently increase the potential occurrence of various infectious and neoplastic processes. Second, RANKL expression upregulates nuclear factor IB (NFIB), which is associated with decreased vulnerability to various nuclear oncogenes [37-38]. Thus, the inhibition of RANKL expression by denosumab therapy is expected to promote osteosarcoma carcinogenesis by increasing predisposition to various nuclear oncogenes. Third, RANKL expression upregulates semaphorin 3A gene expression in osteosarcoma cell lines [38], and knockout of this gene stimulates deregulated bone and cartilage growth [39]. Thus, the inhibition of RANKL expression by denosumab therapy is expected to induce abnormal 
proliferation and differentiation of osteoblasts and bring about semaphorin 3A-mediated osteosarcoma carcinogenesis.

Furthermore, from a technical point of view, a potential hypothesis has been proposed to account for the sarcomatous transformation of GCTB that takes place during or after denosumab therapy. This hypothesis takes into account that osteosarcoma arising in a histologically benign GCTB may encompass some scattered foci of malignant tumor. These foci of malignant tumor (osteosarcoma) may have been missed by means of sampling error at the time of initial core biopsy [11,40]. Moreover, it should be noted that confounding factors (for example, age, gender, and previous treatment with selective intra-arterial embolization) may play contributing roles to the malignant sarcomatous transformation seen in GCTB patients treated with denosumab therapy. This is an interesting topic for future research exploration.

In literature, apart from the sarcomatous transformation, a wide variety of morphological transformation of GCTB has been reported during and after denosumab therapy. For instance, some authors described growth patterns resembling osteoblastoma [41], fibrous histiocytoma [42-43] and an aggressive form of osteoid osteoma that looks like osteosarcoma [44-45]. Moreover, it has been speculated that morphological transformations may be correlated with the duration of denosumab therapy [45]. For example, short-term denosumab therapy will result in early excised lesions displaying spindle-shaped cell stroma, whereas longterm denosumab therapy will result in later excised lesions displaying more dense bone disposition resembling low-grade central osteosarcoma or fibrous dysplasia. Wojcik and partners [45] pinpointed that denosumab-treated GCTB exhibit an extent of structural overlap with malignant GCTB. Thus, careful history documentation of previous denosumab administration is vital to circumvent a possible misdiagnosis of malignant GCTB.

At the present time, the optimal duration of denosumab therapy is not yet established. In addition, whether the duration of denosumab therapy is directly associated with the increased potential of developing sarcomatous transformation of GCTB remains poorly defined. Nevertheless, long-term treatment with denosumab therapy should be limited to the minimum possible in order to avoid dose-dependent toxicity side effects, for example, osteonecrosis of the jaw [46].

Lastly, it should be noted that this review article may not be reporting all the cases of malignant sarcomatous transformation of GCTB, as under-reporting of such cases by healthcare centers remains a possibility. Thus, the number of related cases reported in this review $(n=11)$ may not represent the actual figure.

\section{Conclusions}

In conclusion, healthcare providers should be aware that malignant sarcomatous transformation of GCTB during or after denosumab therapy is a possible consequence. To the best of knowledge, $11(n=11)$ related cases have been reported so far in the English literature. The exact mechanisms or triggering factors by which sarcomatous transformation of GCTB occurs during or after denosumab therapy are poorly defined. Additional isolated case reports and large-sized cohort studies are needed to thoroughly explore a causal association between the malignant sarcomatous transformation of GCTB and denosumab therapy.

\section{Additional Information \\ Disclosures}

Conflicts of interest: In compliance with the ICMJE uniform disclosure form, all authors declare the following: Payment/services info: All authors have declared that no financial support was received from any organization for the submitted work. Financial relationships: All authors have declared that they have no financial relationships at present or within the previous three years with any organizations that might have an interest in the submitted work. Other relationships: All authors have declared that there are no other relationships or activities that could appear to have influenced the submitted work.

\section{References}

1. Turcotte RE: Giant cell tumor of bone. Orthop Clin North Am. 2006, 37:35-51. 10.1016/j.ocl.2005.08.005

2. Skubitz KM: Giant cell tumor of bone: current treatment options . Curr Treat Options Oncol. 2014, 15:50718. 10.1007/s11864-014-0289-1

3. Thomas D, Henshaw R, Skubitz K, et al.: Denosumab in patients with giant-cell tumour of bone: an openlabel, phase 2 study. Lancet Oncol. 2010, 11:275-80. 10.1016/S1470-2045(10)70010-3

4. Jamshidi K, Gharehdaghi M, Hajialiloo SS, Mirkazemi M, Ghaffarzadehgan K, Izanloo A: Denosumab in patients with giant cell tumor and its recurrence: a systematic review. Arch Bone Jt Surg. 2018, 6:260-8. 10.22038/ABJS.2018.25254.1665

5. Balke M, Ahrens H, Streitbuerger A, et al.: Treatment options for recurrent giant cell tumors of bone . J Cancer Res Clin Oncol. 2009, 135:149-58. 10.1007/s00432-008-0427-x

6. van der Heijden L, Dijkstra PD, van de Sande MA, et al.: The clinical approach toward giant cell tumor of bone. Oncologist. 2014, 19:550-61. 10.1634/theoncologist.2013-0432

7. Atkins GJ, Haynes DR, Graves SE, et al.: Expression of osteoclast differentiation signals by stromal elements 
of giant cell tumors. J Bone Miner Res. 2000, 15:640-9. 10.1359/jbmr.2000.15.4.640

8. Thomas DM: RANKL, denosumab, and giant cell tumor of bone. Curr Opin Oncol. 2012, 24:397-403. 10.1097/CCO.0b013e328354c129

9. Gaston CL, Grimer RJ, Parry M, et al.: Current status and unanswered questions on the use of Denosumab in giant cell tumor of bone. Clin Sarcoma Res. 2016, 6:15. 10.1186/s13569-016-0056-0

10. Chawla S, Henshaw R, Seeger L, et al.: Safety and efficacy of denosumab for adults and skeletally mature adolescents with giant cell tumour of bone: interim analysis of an open-label, parallel-group, phase 2 study. Lancet Oncol. 2013, 14:901-8. 10.1016/S1470-2045(13)70277-8

11. Rutkowski P, Ferrari S, Grimer RJ, et al.: Surgical downstaging in an open-label phase II trial of denosumab in patients with giant cell tumor of bone. Ann Surg Oncol. 2015, 22:2860-8. 10.1245/s10434-015-4634-9

12. Rutkowski P, Gaston L, Borkowska A, et al.: Denosumab treatment of inoperable or locally advanced giant cell tumor of bone - multicenter analysis outside clinical trial. Eur J Surg Oncol. 2018, 44:1384-90. 10.1016/j.ejso.2018.03.020

13. Traub F, Singh J, Dickson BC, et al.: Efficacy of denosumab in joint preservation for patients with giant cell tumour of the bone. Eur J Cancer. 2016, 59:1-12. 10.1016/j.ejca.2016.01.006

14. Muller DA, Beltrami G, Scoccianti G, Campanacci DA, Franchi A, Capanna R: Risks and benefits of combining denosumab and surgery in giant cell tumor of bone-a case series. World J Surg Oncol. 2016, 14:281. 10.1186/s12957-016-1034-y

15. Borkowska A, Goryn T, Pienkowski A, et al.: Denosumab treatment of inoperable or locally advanced giant cell tumor of bone. Oncol Lett. 2016, 12:4312-8. 10.3892/ol.2016.5246

16. Dubory A, Missenard G, Domont J, Court C: Interest of denosumab for the treatment of giant-cells tumors and aneurysmal bone cysts of the spine. Spine (Phila Pa 1976). 2016, 41:E654-60. 10.1097/BRS.0000000000001350

17. Rekhi B, Verma V, Gulia A, et al.: Clinicopathological features of a series of 27 cases of post-denosumab treated giant cell tumors of bones: a single institutional experience at a tertiary cancer referral centre, India. Pathol Oncol Res. 2017, 23:157-64. 10.1007/s12253-016-0123-0

18. Deveci MA, Paydas S, Gonlusen G, Ozkan C, Bicer OS, Tekin M: Clinical and pathological results of denosumab treatment for giant cell tumors of bone: prospective study of 14 cases. Acta Orthop Traumatol Turc. 2017, 51:1-6. 10.1016/j.aott.2016.03.004

19. Chen Z, Yang Y, Guo W, et al.: Therapeutic benefits of neoadjuvant and post-operative denosumab on sacral giant cell tumor: a retrospective cohort study of 30 cases. J buon. 2018, 23:453-9.

20. Urakawa H, Yonemoto T, Matsumoto S, et al.: Clinical outcome of primary giant cell tumor of bone after curettage with or without perioperative denosumab in Japan: from a questionnaire for JCOG 1610 study. World J Surg Oncol. 2018, 16:160. 10.1186/s12957-018-1459-6

21. Kumar R, Meis JM, Amini B, et al.: Giant cell tumor of cervical spine presenting as acute asphyxia: successful surgical resection after down-staging with denosumab. Spine (Phila Pa 1976). 2017, 41:E629-32. 10.1097/BRS.0000000000001951

22. Semionov A, Kosiuk J: Giant cell tumor of a rib following denosumab treatment . Radiol Case Rep. 2018, 13:1018-20. 10.1016/j.radcr.2018.04.005

23. Nasser H, Dhanekula A, Abdulhak M, Mott M, Hammoud ZT: Giant cell tumor of bone presenting as left posteromedial chest wall tumor. Ann Thorac Surg. 2018, 106:e89-91. 10.1016/j.athoracsur.2018.02.053

24. Tordjman M, Larousserie F, Mompoint D, Biau D, Lebreton C, Carlier RY: Giant cell tumor of the ischium: imaging findings before and after neoadjuvant denosumab. Diagn Interv Imaging. 2017, 98:447-50. 10.1016/j.diii.2017.01.013

25. Kadowaki M, Yamamoto S, Uchio Y: Late malignant transformation of giant cell tumor of bone 41 years after primary surgery. Orthopedics. 2012, 35:e1566-70. 10.3928/01477447-20120919-32

26. Grote HJ, Braun M, Kalinski T, et al.: Spontaneous malignant transformation of conventional giant cell tumor. Skeletal Radiol. 2004, 33:169-75. 10.1007/s00256-003-0682-5

27. Brien EW, Mirra JM, Kessler S, Suen M, Ho JK, Yang WT: Benign giant cell tumor of bone with osteosarcomatous transformation ("dedifferentiated" primary malignant GCT): report of two cases. Skeletal Radiol. 1997, 26:246-55. 10.1007/s002560050230

28. Takesako H, Osaka E, Yoshida Y, Sugitani M, Tokuhashi Y: Secondary malignant giant cell tumor of bone due to malignant transformation 40 years after surgery without radiation therapy, presenting as fever of unknown origin: a case report. J Med Case Rep. 2016, 10:47. 10.1186/s13256-016-0833-7

29. Errani C, Tsukamoto S, Leone G, et al.: Denosumab may increase the risk of local recurrence in patients with giant-cell tumor of bone treated with curettage. J Bone Joint Surg Am. 2018, 100:496-504. 10.2106/JBJS.17.00057

30. Aponte-Tinao LA, Piuzzi NS, Roitman P, Farfalli GL: A high-grade sarcoma arising in a patient with recurrent benign giant cell tumor of the proximal tibia while receiving treatment with denosumab. Clin Orthop Relat Res. 2015, 473:3050-5. 10.1007/s11999-015-4249-2

31. Broehm CJ, Garbrecht EL, Wood J, Bocklage T: Two cases of sarcoma arising in giant cell tumor of bone treated with denosumab. Case Rep Med. 2015, 2015:767198. 10.1155/2015/767198

32. Park A, Cipriano CA, Hill K, Kyriakos M, McDonald DJ: Malignant transformation of a giant cell tumor of bone treated with denosumab: a case report. JBJS Case Connect. 2016, 6:e78. 10.2106/JBJS.CC.16.00024

33. Tsukamoto S, Righi A, Vanel D, Honoki K, Donati DM, Errani C: Development of high-grade osteosarcoma in a patient with recurrent giant cell tumor of the ischium while receiving treatment with denosumab. Jpn J Clin Oncol. 2017, 47:1090-6. 10.1093/jjco/hyx112

34. Criscitiello C, Viale G, Gelao L, et al.: Crosstalk between bone niche and immune system: osteoimmunology signaling as a potential target for cancer treatment. Cancer Treat Rev. 2015, 41:61-8. 10.1016/j.ctrv.2014.12.001

35. Ellis GK, Bone HG, Chlebowski R, et al.: Randomized trial of denosumab in patients receiving adjuvant aromatase inhibitors for nonmetastatic breast cancer. J Clin Oncol. 2008, 26:4875-82. 10.1200/JCO.2008.16.3832

36. Smith MR, Egerdie B, Hernandez Toriz N, et al.: Denosumab in men receiving androgen-deprivation therapy 


\section{Cureus}

for prostate cancer. N Engl J Med. 2009, 361:745-55. 10.1056/NEJMoa0809003

37. Schuur ER, Kruse U, Iacovoni JS, Vogt PK: Nuclear factor I interferes with transformation induced by nuclear oncogenes. Cell Growth Differ. 1995, 6:219-27.

38. Mori K, Berreur M, Blanchard F, et al.: Receptor activator of nuclear factor-kappaB ligand (RANKL) directly modulates the gene expression profile of RANK-positive Saos-2 human osteosarcoma cells. Oncol Rep. 2007, 18:1365-71. 10.3892/or.18.6.1365

39. Behar O, Golden JA, Mashimo H, Schoen FJ, Fishman MC: Semaphorin III is needed for normal patterning and growth of nerves, bones and heart. Nature. 1996, 383:525-8. 10.1038/383525a0

40. Bertoni F, Bacchini P, Staals EL: Malignancy in giant cell tumor of bone. Cancer. 2003, 97:2520-9. 10.1002/cncr.11359

41. Zhang Y, Ilaslan H, Krishnaney AA, Bauer TW: Morphological transformation of giant-cell tumor of bone after treatment with denosumab: a case report. JBJS Case Connect. 2016, 6:e74. 10.2106/JBJS.CC.16.00015

42. Girolami I, Mancini I, Simoni A, et al.: Denosumab treated giant cell tumour of bone: a morphological, immunohistochemical and molecular analysis of a series. J Clin Pathol. 2016, 69:240-7. 10.1136/jclinpath2015-203248

43. Hakozaki M TT, Yamada H, Hasegawa O, Tasaki K, Watanabe K, Konno S: Radiological and pathological characteristics of giant cell tumor of bone treated with denosumab. Diagn Pathol. 2014, 9:111. 10.1186/1746-1596-9-111

44. Santosh N, Mayerson JL, Iwenofu OH: Pseudosarcomatous spindle cell proliferation with osteoid matrix mimicking osteosarcoma: a distinct histologic phenotype in giant cell tumor of bone following denosumab therapy. Appl Immunohistochem Mol Morphol. 2016, 24:e18-9. 10.1097/PAI.0000000000000165

45. Wojcik J, Rosenberg AE, Bredella MA, et al.: Denosumab-treated giant cell tumor of bone exhibits morphologic overlap with malignant giant cell tumor of bone. Am J Surg Pathol. 2016, 40:72-80. 10.1097/PAS.0000000000000506

46. Palmerini E, Chawla NS, Ferrari S, et al.: Denosumab in advanced/unresectable giant-cell tumour of bone (GCTB): for how long?. Eur J Cancer. 2017, 76:118-24. 10.1016/j.ejca.2017.01.028 